\title{
BMJ Primary healthcare costs associated open with sleep problems up to age 7 years: Australian population-based study
}

\author{
J Quach, ${ }^{1,2}$ L Gold, ${ }^{3}$ H Hiscock, ${ }^{1,2,4}$ F K Mensah, , ${ }^{1,4,5}$ N Lucas, ${ }^{1,6}$ J M Nicholson, , ${ }^{1,6}$ \\ M Wake ${ }^{1,2,4}$
}

To cite: Quach J, Gold L, Hiscock $\mathrm{H}$, et al. Primary healthcare costs associated with sleep problems up to age 7 years: Australian population-based study. BMJ Open 2013;3:e002419. doi:10.1136/bmjopen-2012002419

- Prepublication history and additional material for this paper are available online. To view these files please visit the journal online (http://dx.doi.org/10.1136/ bmjopen-2012-002419).

Received 30 November 2012 Accepted 5 April 2013

This final article is available for use under the terms of the Creative Commons Attribution Non-Commercial 2.0 Licence; see http://bmjopen.bmj.com

For numbered affiliations see end of article

Correspondence to Dr Jon Quach; jon.quach@mcri.edu.au

\section{ABSTRACT}

Objectives: In Australian 0-7-year olds with and without sleep problems, to compare (1) type and costs to government of non-hospital healthcare services and prescription medication in each year of age and (2) the cumulative costs according to persistence of the sleep problem.

Design: Cross-sectional and longitudinal data from a longitudinal population study.

Setting: Data from two cohorts participating in the first two waves of the nationally representative Longitudinal Study of Australian Children.

Participants: Baby cohort at ages 0-1 and 2-3 $(\mathrm{n}=5107,4606)$ and Kindergarten cohort at ages $4-5$ and 6-7 ( $\mathrm{n}=4983,4460)$.

Measurements: Federal Government expenditure on healthcare attendances and prescription medication from birth to 8 years, calculated via linkage to Australian Medicare data, were compared according to parent report of child sleep problems at each of the surveys.

Results: At both waves and in both cohorts, over $92 \%$ of children had both sleep and Medicare data. The average additional healthcare costs for children with sleep problems ranged from $\$ 141$ (age 5) to $\$ 43$ (age 7), falling to $\$ 98$ (age 5) to $\$ 18$ (age 7) per child per annum once family socioeconomic position, child gender, global health and special healthcare needs were taken into account. This equates to an estimated additional $\$ 27.5$ million (95\% Cl $\$ 9.2$ to $\$ 46.8$ million) cost to the Australian federal government every year for all children aged between 0 and 7 years. In both cohorts, costs were higher for persistent than transient sleep problems.

Conclusions: Higher healthcare costs were sustained by infants and children with sleep problems. This supports ongoing economic evaluations of early prevention and intervention services for sleep problems considering impacts not only on the child and family but also on the healthcare system.

\section{INTRODUCTION}

Up to $40 \%$ of parents report that their infants and young children experience sleep problems, ${ }^{1-3}$ which are in turn associated

\section{ARTICLE SUMMARY}

\section{Article focus}

- Up to $40 \%$ of infants and children experience sleep problems, which are associated with poorer health and academic outcomes.

- These problems are treatable but, until their avoidable health cost burden is made clear, it is unlikely that these effective programmes will be made more widely available.

\section{Key messages}

- Sleep problems in infants and children account for substantial primary healthcare costs to the public purse.

- Persistent problems are associated with the greatest costs.

- The study suggests that population healthcare expenditures could be reduced if sleep interventions can be provided cost-effectively.

Strengths and limitations of the study

- Healthcare costs reported using administrative data used by the Australian government to fund the healthcare system

- Generalisability and precision of findings through a nationally-representative sampling frame, large sample size and high retention rate.

- Despite the marked increases associated with sleep problems, this study cannot infer causality because data does not specifically separate the costs of seeking and receiving help for the sleep problem itself from the costs of seeking help for other conditions.

with increased child inattention, poorer social and emotional skills and poorer learning and memory formation. ${ }^{4-9}$ They are also of great concern to parents, ${ }^{10}$ and are associated with disruptions to employment and increased mental health problems. ${ }^{11-13}$ Most sleep problems in this age group are behavioural in nature, for example, difficulty settling to sleep and frequent night waking. Fortunately effective treatments are available $^{14-16}$ and these can actually save on costs. ${ }^{15} 17$ 
Additional healthcare costs associated with sleep problems could reflect the increased use of household and community resources invested in addressing sleep problems, to their comorbidities, or to any underlying condition leading to the sleep problem. ${ }^{18}$ Such population costs have been reported for several common and important childhood health conditions such as attention-deficient/hyperactivity disorder (ADHD), overweight and autism. ${ }^{19-21}$ If the increases in healthcare costs between those with and without sleep problems are substantial, these excess costs would provide a strong driver for implementing more systematic prevention and treatment.

The healthcare costs of sleep problems have been reported in adults. ${ }^{22-26}$ One Australian study reported sleep problems cost $\$ 146$ million annually in 2004, with an additional \$313 million for associated conditions. ${ }^{22}$ The Canadian government incurs a \$191.2 million annual healthcare burden for health consultations for patients suffering from insomnia in 2002. ${ }^{26}$ However, being restricted to the costs directly associated with a diagnosed sleep problem, these adult studies do not include the costs associated with seeking a diagnosis or managing the excess comorbidities experienced by these individuals.

To date, there is very limited data on the population healthcare costs associated with childhood sleep problems in Australia and internationally. Increased costs and healthcare use have been reported in clinical groups when compared to matched controls. ${ }^{27-29}$ However, these studies have focused on children with obstructive sleep apnoea, which is less common in children than behavioural problems. ${ }^{1}$ While two other studies have reported lower healthcare costs for offering compared with not offering families a sleep intervention. ${ }^{15} 17$ However, these studies were restricted to infants less than 1 year of age and provided the intervention following a community-based screening procedure. Although highly cost-effective, these population-based programmes have not yet been widely implemented beyond the infant age group.

Therefore, this study aims to provide the first population healthcare costs of childhood sleep problems. This study uses data from the first two biennial waves of a large, nationally representative Australian study spanning the first 8 years of life. Drawing on the Medicare schemes that record subsidies made for visits by virtually all Australians to family doctors/specialists and their prescription medications, we aimed to determine

1 The type and costs to government of non-hospital based healthcare services in each year of life for infants and children aged 0-7 years with, compared to without, sleep problems;

2 The cumulative costs according to whether sleep problems are absent, transient (ie, occur in one but not both waves) or persistent (ie, occur in both waves of data collection).

\section{METHODS}

\section{Study design and sample}

Data were drawn from the first two waves of the nationally representative Longitudinal Study of Australian Children (LSAC), whose design and sample are described elsewhere. ${ }^{30}$ Briefly, LSAC employed a twostage cluster sampling design to simultaneously create two independent cohorts, birth (B cohort) and preschool (K cohort). Postcodes (except the most remote) were sampled after stratifying by state of residence and urban versus rural status to ensure proportional geographic representation. The final sampling frame then comprised all children in the relevant age ranges enrolled in the Australian Medicare database, within which $98 \%$ of all Australian children are registered, with children within each selected postcode randomly selected to populate both the B and $\mathrm{K}$ cohorts. Both cohorts were recruited in 2004 for wave 1 and followed up 2 years later in wave 2 .

For the overall LSAC study, in the B cohort, 5107 infants aged $0-1$ years participated in wave 1 (2004) and $4606(90 \%)$ were retained as 2-3-year-old toddlers in wave 2 (2006); for the $\mathrm{K}$ cohort, 4983 children age 45 years took part in wave 1, with $4464(90 \%)$ retained as 6-7 year olds in wave 2. Figure 1 shows the number of children at each data collection time point, the number of children with complete sleep and Medicare data at each wave and also the final grouping within waves by exact year of age used for this study.

The study was approved by the Australian Institute of Family Studies Ethics Committee, and a parent provided written informed consent to participate and to access Medicare data for every participant.

\section{Procedures}

At both waves, data were collected by trained researchers via primary caregiver interview in the family home. Healthcare costs data were subsequently obtained by linkage with Medicare Australia data (see below). Data linkage was completed for 9375 (93\%) children.

\section{Measures}

\section{Child sleep problem (exposure/independent variable)}

Using the same question at each wave and for both cohorts, the primary caregiver reported whether or not they considered the study infant/child to have a sleep problem (no, mild, moderate or severe problem). This was dichotomised into no/mild (no sleep problem) versus moderate/severe (sleep problem) because parent perception of a more severe sleep problem is a motivator to seek help, and this dichotomisation is comparable to published cross-sectional and intervention research using the same item. ${ }^{2} 51216$ Parent report was used because parent perception of a sleep problem is a key driver of help-seeking behaviour; subjective measures of sleep are more cost-effective and feasible compared to objective measures in large population-based settings $^{31}$; and what constitutes a sleep problem from a 
Figure 1 Participant flow for the two LSAC cohorts.
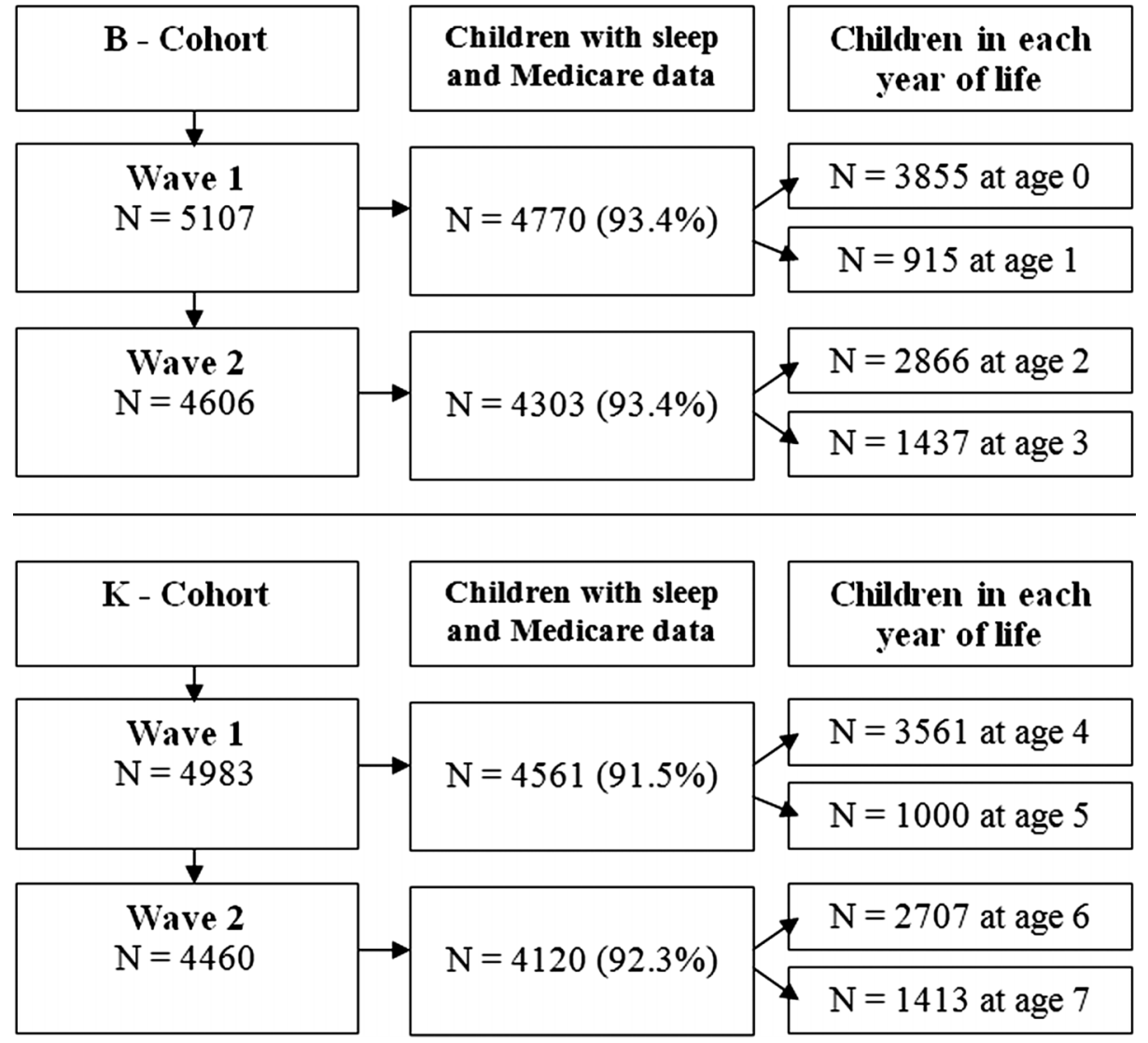

research perspective remains widely debated. ${ }^{32}$ Because sleep problems can be transient and thus vary from year to year, sleep problems and their associated Medicare costs were calculated for each year of life in which each child's sleep was reported, for example whether a wave 1 (0-1 year) infant was aged 0 or 1 year at the time of data collection.

\section{Healthcare system costs (dependent variable)}

Data from the national Medicare Benefit Schedule (MBS) and Pharmaceutical Benefits Scheme (PBS) were used to estimate the costs to the Australian government of subsidised prescription medication and healthcare attendances. ${ }^{33}{ }^{34}$ Jointly, the MBS and PBS comprise the Australian Medicare subsidised healthcare scheme. In Australia, both Federal and State governments provide funding for public hospitals (not considered in this study). Through the MBS, the Federal government also subsidises non-hospital based medical practitioners for providing care up to a pre-determined amount, with the remainder (typically around $15 \%$ ) paid by the patient. Most services covered by MBS are visits to healthcare professionals, although it also includes non-hospital diagnostic and pathology services and treatment. ${ }^{33} 34$ The costs of pharmaceuticals are subsidised by the PBS, in which a pre-determined list of medications and formulas are subsidised for approximately $83 \%$ of the medication costs with the remainder paid by the patient. The metrics reported in this paper represent the reimbursement for healthcare and medication costs provided by the Australian Federal Government. While recognising this is a proxy for the actual cost, we refer to this as 'costs' as we present these analyses.

MBS costs were inflated to 2012 Australian dollars $(\$ A 1=£ 0.65$, November 2012) using the consumer price index figures provided by the Australian Bureau of Statistics (http://www.abs.gov.au). Costs for each child were estimated for each year of life and also for the full 4-year period, and covered all costs incurred between 2004 and 2009 for each cohort. For the B cohort, costs were available from the child's birth until the child's fourth birthday (0-3 years of life); for the $\mathrm{K}$ cohort, costs were available from the child's fourth to eighth birthday (4-7 years of life).

\section{Potential confounders}

Family socioeconomic position (SEP), ${ }^{35}{ }^{36}$ child gender, $^{12}{ }^{37}$ global health ${ }^{38}$ and special healthcare needs $(\mathrm{SHCN})^{39}$ may all be related to both sleep problems and healthcare utilisation so were considered as potential confounding factors. Family SEP, released with the LSAC dataset for each wave, is derived from standardised scores for three variables: combined annual household income, parents' years of education and parents' occupation. Child global health was measured at each wave by parent response to "In general, how would you 
say your child's current health is?"; responses dichotomised into 'excellent/very good' versus 'good/fair/poor'. SHCN was measured at each wave using the two-item short form of the parent-reported Children with Special Health Care Needs Screener. ${ }^{40}$ The measure identifies children who had a medical, behavioural or other health condition that has lasted or is expected to last at least 1 year, and who require (1) more medical care, mental health services or education services or (2) more prescription medication, as a result of their condition, than other children of the same age.

\section{Statistical analysis}

Analyses were conducted using Stata V.11.0, using survey methods to weight the analyses to account for the unequal probability of participant selection into the sample, non-response and sample attrition and the multistage, clustered sampling design. ${ }^{414}$

For aim 1, healthcare service costs were calculated for each child's year of life in which it was used, with all 8 years of life from year $0-7$ years of age well represented. The association between sleep problems and both the number and cost of healthcare services used (MBS, PBS and combined Medicare healthcare costs) was determined for each year of life. Linear regression was used to estimate the mean differences between those with and without sleep problems, in both unadjusted analyses and analyses adjusted for the potential confounders. Because of substantial skewing in service use and costs data, the standard model-based CIs for the mean differences between groups were also validated using the bias-corrected accelerated bootstrap method. ${ }^{43}$ The method of bootstrapping could not be implemented while accounting for complex survey design in Stata by first-order Taylor linearisation; however, comparison of unweighted means with and without bootstrapping revealed very small differences. Utilisation of standard linear regression techniques for highly skewed cost data is supported in large public health datasets. ${ }^{44}$
Mean between-group differences for each year of age were multiplied by Australian 2009 population statistics to estimate the population-level additional healthcare costs associated with children with reported sleep problems. ${ }^{45}$

The cumulative costs associated with persistence of sleep problems over the two 4-year spans (aim 2) were determined using unadjusted and adjusted (for the same potential confounders as above) linear regression to estimate the mean difference between those with sleep problems at neither, one or both waves within each of the $\mathrm{B}$ and $\mathrm{K}$ cohorts. Tests for trend were carried out within the regression models by including sleep problem persistence (neither, one or both waves) as a linear predictor.

\section{RESULTS}

\section{Sample characteristics}

Figure 1 shows that sleep data and Medicare data were available for over $92 \%$ of respondents in both the cohorts at both waves having sleep data. Overall, there were 3855 children aged 0,915 aged 1, 2886 aged 2, 1437 aged 3, 3561 aged 4, 1000 aged 5, 2707 aged 6 and 1413 aged 7 years In addition, $3998(78.2 \%)$ children in the B cohort had complete sleep and Medicare data at both waves while $3880(77.9 \%)$ children in the $\mathrm{K}$ cohort had data at both waves.

The proportion of children with moderate-severe sleep problems ranged from $17.7 \%$ at age 0 to $7 \%$ at age 7. Table 1 shows that, for both cohorts, children with sleep problems at wave 1 were more likely to have concomitant fair/poor global health and SHCN compared to children who did not.

\section{Healthcare service use and costs for those with and} without sleep problems (aim 1)

In every year of age, children with sleep problems accessed more medical services per year than children without. Throughout the first 8 years of life, the family

Table 1 Sociodemographic characteristics and children's health

\begin{tabular}{|c|c|c|c|c|}
\hline \multirow[b]{2}{*}{ Variable (wave 1) } & \multicolumn{2}{|l|}{ B cohort (infant) } & \multicolumn{2}{|c|}{ K cohort (preschool) } \\
\hline & No sleep problem & Sleep problem & No sleep problem & Sleep problem \\
\hline Sample size $(n)$ & 3960 & 810 & 3942 & 619 \\
\hline Child age in years (mean (SD)) & $0.8(0.2)$ & $0.8(0.2)$ & $4.8(0.2)$ & $4.8(0.2)$ \\
\hline Male $(\%)$ & 50.9 & 54.6 & 51.0 & 52.5 \\
\hline Special healthcare needs (\%) & 5.3 & 9.9 & 12.1 & 21.2 \\
\hline Global health poor/fair (\%) & 2.9 & 5.5 & 2.0 & 5.6 \\
\hline Married/cohabiting (\%) & 90.2 & 90.9 & 86.6 & 84.5 \\
\hline Primary language is English (\%) & 78.9 & 78.5 & 83.6 & 87.7 \\
\hline Mother completed high school (\%) & 66.5 & 69.0 & 59.2 & 51.9 \\
\hline \multicolumn{5}{|l|}{ Socioeconomic quintile (\%) } \\
\hline Lowest & 14.6 & 12.3 & 11.2 & 16.1 \\
\hline Highest & 23.5 & 26.5 & 22.0 & 16.8 \\
\hline
\end{tabular}


doctor was the most frequently used health service, accounting for over $60 \%$ of all healthcare costs, with specialist doctors the second most common at $10-20 \%$ (see online supplementary appendices 1 and 2). Use of both family and specialist doctors was higher for children with than without sleep problems. Table 2 shows that mean MBS, PBS and combined Medicare costs were higher for infants and children with sleep problems compared to those without at all ages. Adjusting for sociodemographic characteristics, child global health and SHCN attenuated the estimated mean differences, which nonetheless remained statistically strong for medical service (MBS) costs for children. However, the differences in pharmaceutical (PBS) costs were small and associations therefore weak.

There was a consistent pattern of higher combined Medicare costs (MBS + PBS) for children across all of the ages (see table 3). The mean excess costs of combined medical services for 1 year per child with a sleep problem ranged from $\$ \mathrm{~A} 43$ at 7 years to $\$ \mathrm{~A} 141$ at 5 years, falling to an estimated $\$ A 18$ at age 7 years to $\$ A 98$ at age 5 years once the effect of confounders was accounted for. Extrapolating to the Australian population, the additional costs to the Australian government for children experiencing sleep problems are estimated to be between $\$ 810335$ (for all Australian 7-year olds) and $\$ 5.2$ million (for all Australian 0 -year olds) per annum for each of the first 7 years of children's lives. For the entire population of Australian 07-years old children, we therefore estimate that sleep problems are associated with at least an additional $\$ 27.5$ million (95\% CI $\$ 9.2$ to $\$ 46.8$ million) cost to government every year. Even after adjusting for the effect of confounders, our estimates still suggest an additional $\$ 15.8$ million (95\% CI $\$ 0.2$ to $\$ 32.9$ million) cost to government.

\section{Cumulative healthcare costs over 4 years by persistence of sleep problems (aim 2)}

In the first 4 years of life, $75.2 \%, 20.3 \%$ and $4.5 \%$ of B cohort children had a sleep problem at neither, one or both waves, respectively. Similarly, between 4 and 7 years of age, $84.1 \%, 13.0 \%$ and $2.9 \%$ of $\mathrm{K}$ cohort children had a sleep problem at neither, one or both waves, respectively. In both the cohorts, and for all of MBS, PBS and combined Medicare services, there was a trend whereby costs tended to be higher with increasing persistence of sleep problems (table 4).

\section{DISCUSSION}

Sleep problems across the first 7 years of life were associated with an increased cost to the Australian healthcare system, estimated as an excess annual burden of $\$ 27.5$ million (95\% CI $\$ 9.2$ to $\$ 46.8$ million). The extent of the cost differential for sleep problems experienced in each of the first 8 years of life ( $\$ 43$ to $\$ 141$, or $\$ 18$ to $\$ 98$ per child when adjusted) is sufficient to be of potential significance to policy and healthcare costs were found to increase with greater persistence of sleep problems.

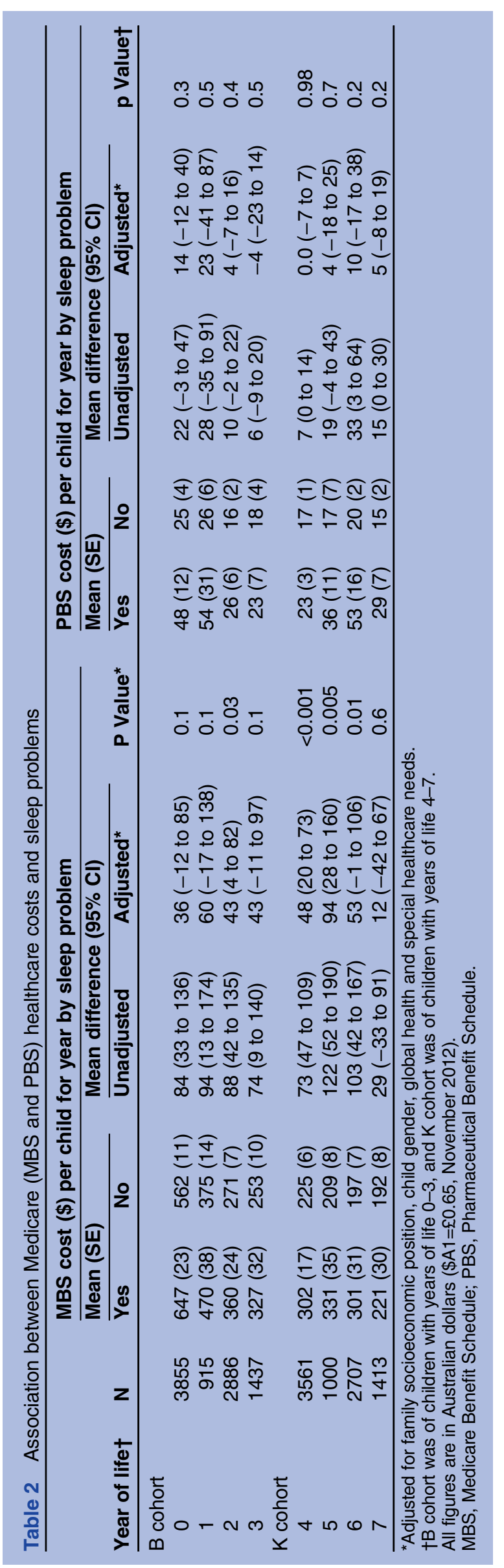




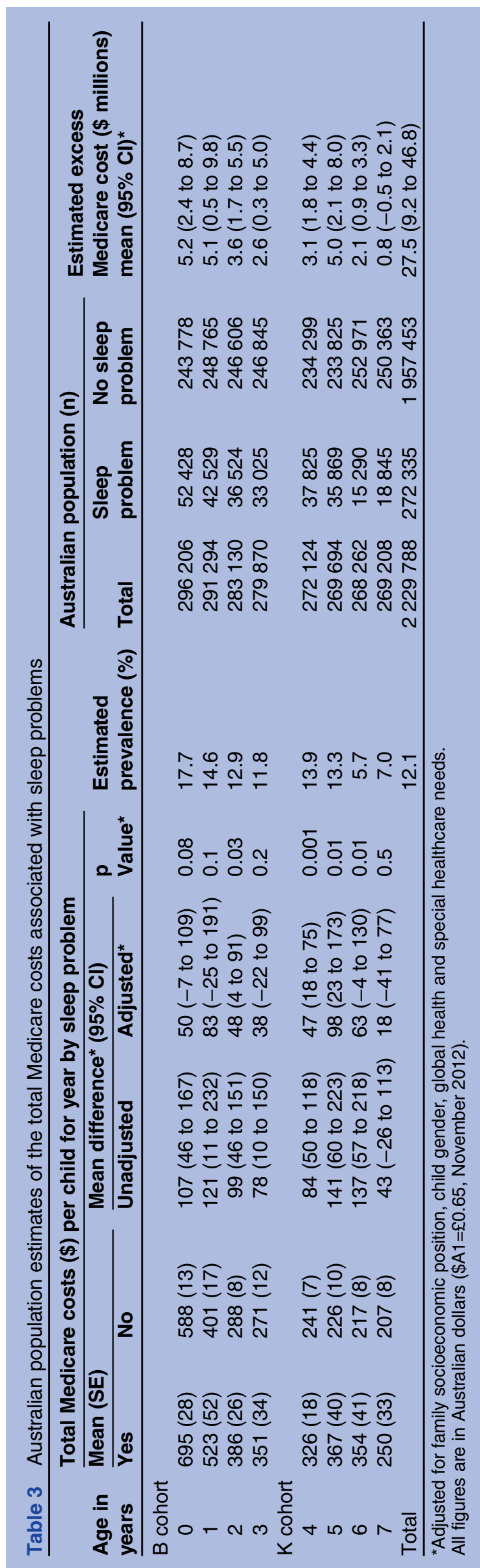

Higher healthcare costs have previously been associated with sleep problems in adult populations, ${ }^{22-25}$ but these studies have focused only on the postdiagnosis costs of sleep problems that are frequently organic such as obstructive sleep apnoea. ${ }^{22}$ In infants and children, parent concern about their child's sleep may be a motivator to access health services for medical advice for child sleep or associated comorbidities. Regardless of whether a sleep problem is diagnosed, the costs associated with generally seeking advice contribute to the overall costs in the Australian system and need to be considered, especially since increased costs remain even when accounting for child global health and SHCN. Further, as infants and children are more likely to have a behaviourally based sleep problem, ${ }^{1}$ the costs to diagnose and treat sleep problems is likely to differ between paediatric and adult populations.

The study had a number of strengths. It is the first study to quantify excess healthcare utilisation and costs to governments incurred by infants and children with sleep problems. Our nationally representative sampling frame, large sample size and high retention rate support the generalisability of these findings and yield precise estimates of sleep problem prevalence and associated healthcare costs. Use of the same sleep measure throughout allows consistency of interpretation.

The analyses were based on actual costs recorded via the Australian government administrative data for reimbursement of healthcare benefits. These data are very accurate and are commonly used to inform Australian health policy agenda. ${ }^{46}$ The excess costs associated with sleep problems, however, only reflect the services that are reimbursed by Medicare. The true costs are likely to be much higher, since Medicare excludes inpatient care, costs to educational or other systems and the additional use of family household resources such as time, effort and out of pocket expenses that could well match or exceed the costs to government reported here.

The study also has limitations. Despite the marked increase in costs for those with, compared to without, sleep problems, this study cannot infer that these costs are directly attributable to the sleep problem. Medicare data do not separate the costs of seeking and receiving help for the sleep problem itself from the costs of seeking help for other conditions or the specific type of care sought. Thus the excess costs observed may have also reflected any specific underlying conditions that may have led to the sleep disruption (eg, autism, ADHD) and/or conditions in which symptoms are exacerbated or even caused by disrupted sleep (eg, social and emotional difficulties, learning difficulties). Nonetheless, the fact that the increased costs associated with sleep problems persisted even after accounting for differences in health (overall health and SHCN) between children with and without sleep problems suggests that sleep problems themselves incur increased healthcare costs. 
Table 4 Association between total Medicare costs and persistence of sleep problems

\begin{tabular}{|c|c|c|c|c|c|c|}
\hline \multirow[b]{3}{*}{ Variable } & \multicolumn{6}{|c|}{ Number of times sleep problems reported } \\
\hline & \multirow{2}{*}{$\begin{array}{l}\text { Never } \\
\text { Mean (SE) }\end{array}$} & \multicolumn{2}{|c|}{ Once } & \multicolumn{2}{|l|}{ Twice } & \multirow[b]{2}{*}{$\begin{array}{l}\text { p } \\
\text { Value* }\end{array}$} \\
\hline & & Mean (SE) & $\begin{array}{l}\text { Mean difference } \\
(95 \% \mathrm{Cl})\end{array}$ & Mean (SE) & $\begin{array}{l}\text { Mean difference† } \\
(95 \% \mathrm{Cl})\end{array}$ & \\
\hline $\begin{array}{l}\text { B cohort } \\
\text { (0-3 years) }\end{array}$ & $n=3461(75.2 \%)$ & $n=933(20.3 \%)$ & & $n=208(4.5 \%)$ & & \\
\hline MBS & $1509(27)$ & $1670(53)$ & $68(-27$ to 164$)$ & 2097 (133) & 270 (46 to 494$)$ & 0.007 \\
\hline PBS & $75(9)$ & $138(27)$ & $42(-22$ to 108$)$ & $130(38)$ & $-7(-100$ to 86$)$ & 0.4 \\
\hline $\begin{array}{l}\text { Medicare } \\
\text { total }\end{array}$ & $1584(31)$ & $1807(64)$ & $111(-14$ to 237$)$ & $2226(145)$ & 263 (6 to 519$)$ & 0.01 \\
\hline $\begin{array}{l}\text { K cohort } \\
\text { (4-7 years) }\end{array}$ & $n=3754(84.1 \%)$ & $\mathrm{n}=578(13.0 \%)$ & & $\mathrm{n}=128(2.9 \%)$ & & \\
\hline MBS & $837(20)$ & $1054(48)$ & $80(-23$ to 184$)$ & $1348(108)$ & 264 (92 to 436) & 0.002 \\
\hline PBS & $69(6)$ & $141(23)$ & $26(-17$ to 70$)$ & $237(98)$ & $59(-119$ to 236$)$ & 0.3 \\
\hline $\begin{array}{l}\text { Medicare } \\
\text { total }\end{array}$ & $906(23)$ & $1195(61)$ & $106(-17$ to 231$)$ & 1585 (179) & 322 (67 to 578$)$ & $<0.001$ \\
\hline
\end{tabular}

Another limitation is that the sleep was measured by subjective parent report rather than by more objective measures. However, parent report is the only real option for such a large population-based study, with objective measures such as overnight polysomnography unfeasible in this context and actigraphy an unreliable measure of behavioural sleep difficulties. ${ }^{31}$ In addition, it reflects parent concern, which is the prime motivator for parents to seek medical advice. ${ }^{31} 4748$ Finally, the sleep measure could not distinguish between behavioural (eg, bedtime resistance) and organic (eg, obstructive sleep apnoea) sleep problems and therefore we cannot attribute costs to specific conditions or types of problems.

Despite being associated with a heavy financial burden to the healthcare system, parent-reported infant and child sleep problems barely register on public health agendas. Future research should focus on the effectiveness and costs of prevention and intervention programmes for childhood sleep problems, and delineating to which populations these can most efficiently be targeted. Given the costs increased as sleep problems persisted, we recommend family doctors ask about sleep and, where problems exist, assess these in detail and provide families with suitable sleep management strategies. $^{13}$

\section{Author affiliations \\ ${ }^{1}$ Murdoch Children's Research Institute, Melbourne, Australia \\ ${ }^{2}$ Centre for Community Child Health, Royal Children's Hospital, Melbourne, Australia \\ ${ }^{3}$ Deakin Health Economics, Deakin University, Melbourne, Australia ${ }^{4}$ Department of Paediatrics, University of Melbourne, Parkville, Australia ${ }^{5}$ Clinical Epidemiology and Biostatistics Unit, Royal Children's Hospital, Melbourne, Australia \\ ${ }^{6}$ Parenting Research Centre, Melbourne, Australia}

Contributors JQ lead the overall data analysis and preparation of the manuscript. NL, FKM, LG, MW and JN obtained the data and prepared it for analysis. JQ, MW, HH, FM and LG conducted the data analysis. All authors contributed to the interpretation of findings, preparation of the manuscript and have all approved the final version.

Funding This paper uses confidentialised unit record files from the Longitudinal Study of Australian Children (LSAC) survey. The LSAC project was initiated and is funded by the Commonwealth Department of Families, Housing, Community Services and Indigenous Affairs (FaHCSIA) and is managed by the Australian Institute of Family Studies. The findings and views reported in this paper, however, are those of the authors and should not be attributed to either FaHCSIA or the Australian Institute of Family Studies. Research at the Murdoch Childrens Research Institute is supported by the Victorian Government's Operational Infrastructure Program. The Parenting Research Centre receives funding from the Victorian Government Department of Education and Early Child Development. Australian National Health \& Medical Research Council (NHMRC) Population Health Capacity Building Grants part-supported Drs Mensah, Quach and Ass/Prof Hiscock (436914) and Ass/Prof Gold (425855). Additionally, NHMRC Early Career Fellowships supported Ass/Prof Gold (1035100) and Dr Mensah (1037449), and NHMRC Career Development Awards supported Ass/Prof Hiscock (607351), Prof Wake (546405) and Prof Nicholson (390136). We acknowledge the peer review provided by the LSAC analysis group comprising staff from the Parenting Research Centre and Murdoch Childrens Research Institute.

Competing interests None.

Ethics approval Australian Institute of Family Studies.

Provenance and peer review Not commissioned; externally peer reviewed.

Data sharing statement No additional data are available.

\section{REFERENCES}

1. Owens JA, Witmans M. Sleep problems. Curr Probl Pediatr Adolesc Health Care 2004;34:154-79.

2. Quach J, Hiscock H, Canterford L, et al. Outcomes of child sleep problems over the school-transition period: Australian Population Longitudinal Study. Pediatrics 2009;123:1287-92.

3. Simola P, Laitalainen E, Liukkonen K, et al. Sleep disturbances in a community sample from preschool to school age. Child Care Health Dev 2011;38:572-80.

4. Fifer WP, Byrd DL, Kaku M, et al. Newborn infants learn during sleep. Proc Natl Acad Sci USA 2010;107:10320-3.

5. Hiscock $\mathrm{H}$, Canterford L, Ukoumunne OC, et al. Adverse associations of sleep problems in Australian preschoolers: national population study. Pediatrics 2007;119:86-93. 
6. Holley S, Hill C, Stevenson J. An hour less sleep is a risk factor for childhood conduct problems. Child Care Health Dev 2011;74:444-55.

7. Ravid S, Afek I, Suraiya S, et al. Sleep disturbances are associated with reduced school achievements in first-grade pupils. Dev Neuropsychol 2009;34:574-87.

8. Touchette E, Cote SM, Petit D, et al. Short nighttime sleep-duration and hyperactivity trajectories in early childhood. Pediatrics 2009;124 e985-93.

9. Wilhelm I, Diekelmann S, Born J. Sleep in children improves memory performance on declarative but not procedural tasks. Learn Mem 2008;15:373-7.

10. Milan S, Snow S, Belay S. The context of preschool children's sleep: racial/ethnic differences in sleep locations, routines, and concerns. $J$ Fam Psychol 2007;21:20-8.

11. Hiscock $\mathrm{H}$, Wake M. Infant sleep problems and postnatal depression: a community-based study. Pediatrics 2001;107:1317-22.

12. Martin J, Hiscock $\mathrm{H}$, Hardy $\mathrm{P}$, et al. Adverse associations of infant and child sleep problems and parent health: an Australian population study. Pediatrics 2007;119:947-55.

13. American Academy of Sleep Medicine. AASM: practice guidelines. http://www.aasmnet.org/practiceguidelines.aspx: American Academy of Sleep Medicine, 2008

14. Mindell JA, Owens JA. A clinical guide to pediatric sleep: diagnosis and management of sleep problems. Philadelphia: Lippincott Williams \& Wilkins, 2003.

15. Hiscock H, Bayer J, Gold L, et al. Improving infant sleep and maternal mental health: a cluster randomised trial. Arch Dis Child 2007;92:952-8

16. Quach J, Hiscock H, Ukoumunne OC, et al. A brief sleep intervention improves outcomes in the school entry year: a randomized controlled trial. Pediatrics 2011;128:692-701.

17. Morris S, St James-Roberts I, Sleep J, et al. Economic evaluation of strategies for managing crying and sleeping problems. Arch Dis Child 2001;84:15.

18. Drummond MF, Sculpher MJ, Torrance GW. Methods for the economic evaluation of health care programmes. Oxford University Press, 2005.

19. Harpin VA. The effect of ADHD on the life of an individual, their family, and community from preschool to adult life. Arch Dis Child 2005;90(Suppl 1):i2-7.

20. Estabrooks PA, Shetterly S. The prevalence and health care use of overweight children in an integrated health care system. Arch Pediatr Adolesc Med 2007;161:222-7.

21. Leslie DL, Martin A. Health care expenditures associated with autism spectrum disorders. Arch Pediatr Adolesc Med 2007;161:350-5.

22. Hillman DR, Murphy AS, Pezzullo L. The economic cost of sleep disorders. Sleep 2006;29:299-305.

23. Walsh J, Engelhardt C. The direct economic costs of insomnia in the United States for 1995. Sleep 1999;22:S386-93.

24. AIGhanim N, Comondore VR, Fleetham J, et al. The economic impact of obstructive sleep apnea. Lung 2008;186:7-12.

25. Ozminkowski RJ, Wang S, Walsh JK. The direct and indirect costs of untreated insomnia in adults in the United States. Sleep 2007;30:263-73.

26. Daley M, Morin CM, LeBlanc M, et al. The economic burden of insomnia: direct and indirect costs for individuals with insomnia syndrome, insomnia symptoms, and good sleepers. Sleep 2009;32:55

27. Reuveni $\mathrm{H}$, Simon $\mathrm{T}$, Tal A, et al. Health care services utilization in children with obstructive sleep apnea syndrome. Pediatrics 2002;110:68-72.

28. Tarasiuk A, Greenberg-Dotan S, Simon-Tuval T, et al. Elevated morbidity and health care use in children with obstructive sleep apnea syndrome. Am J Respir Crit Care Med 2007;175:55-61.

29. Tarasiuk A, Simon T, Tal A, et al. Adenotonsillectomy in children with obstructive sleep apnea syndrome reduces health care utilization. Pediatrics 2004;113:351-6.

30. Soloff C, Lawrence D, Johnstone R. LSAC technical reference paper number 1: sample design. 2005. http://www.aifs.gov.au/growingup/ pubs/techpapers/tp1.pdf

31. Iwasaki M, Iwata S, lemura A, et al. Utility of subjective sleep assessment tools for healthy preschool children: a comparative study between sleep logs, questionnaires, and actigraphy. $J$ Epidemiol 2010;20:143-9.

32. Mindell JA, Meltzer LJ. Behavioural sleep disorders in children and adolescents. Ann Acad Med Singapore 2008;37:722-8.

33. Commonwealth Department of Health and Aged Care. The Australian health care system: an outline. Canberra: Australian Institute of Health and Welfare, 2000.

34. Willis E, Reynolds L. Understanding the Australian health care System. Australia: Elsevier, 2008.

35. Buckhalt JA, El-Sheikh M, Keller P. Children's sleep and cognitive functioning: race and socioeconomic status as moderators of effects. Child Dev 2007;78:213-31.

36. Measuring the socio-economic position of families in HILDA and LSAC, 2006.

37. Meijer AM. Chronic sleep reduction, functioning at school and schoo achievement in preadolescents. J Sleep Res 2008;17:395-405.

38. Waters $\mathrm{E}$, Salmon L, Wake M, et al. The child health questionnaire in Australia: reliability, validity and population means. Aust $N Z J$ Public Health 2000;24:207-10.

39. McPherson $\mathrm{M}$, Arango $\mathrm{P}$, Fox $\mathrm{H}$, et al. A new definition of children with special health care needs. Pediatrics 1998;102:137-9.

40. Bethell CD, Read D, Stein REK, et al. Identifying children with special health care needs: development and evaluation of a short screening instrument. Ambul Pediatr 2002;2:38-48.

41. Soloff C, Growing Up in Australia tLSoAC, Studies AloF. Wave 1 weighting and non-response: Australian Institute of Family Studies, 2006.

42. Misson S, Sipthorp M, Studies AloF. Wave 2 weighting and non-response: Australian Institute of Family Studies, 2007.

43. Davison AC, Hinkley DV. Bootstrap methods and their application: Cambridge University Press, 1999.

44. Lumley T, Diehr P, Emerson S, et al. The importance of the normality assumption in large public health data sets. Annu Rev Public Health 2002;23:151-69.

45. Australian Bureau of Statistics. 3201.0-Population by age and sex, Australian states and territories. Canberra: Australian Bureau of Statistics, 2010

46. Medicare Australia. Medicare Australia-annual report 2010-11. Canberra: Commonwealth of Australia, 2011.

47. Bauer K, Blunden S. How accurate is subjective reporting of childhood sleep problems? A review of the literature and the implications for practice. Curr Pediatr Rev 2008;4:132-42.

48. Blunden S, Lushington K, Lorenzen B, et al. Are sleep problems under-recognised in general practice? Arch Dis Child 2004;89:708-12. 